\title{
Care home diabetes: an important part of community diabetology where high standards of diabetes care are essential Role of the National Advisory Panel on Care Home Diabetes (NAPCHD)
}

\author{
ALAN J SINCLAIR, ${ }^{1}$ AHMED H ABDELHAFIZ, ${ }^{2}$ SRI BELLARY ${ }^{3}$
}

Key words: care home, diabetes, quality

Diabetes mellitus affects between one in three and one in four residents of UK care homes and aged-care (long-term care) facilities globally and, apart from dementia, is the commonest disabling disorder in care homes. ${ }^{1}$ The phenotype in residents is usually that of a person with type 2 diabetes (it is unclear what proportion of residents have type 1 diabetes) with an often complex co-morbid illness that leads to frailty, loss of independence, disability and reduced survival. ${ }^{2}$ In addition, residents with diabetes have a high risk of hypoglycaemia and avoidable hospital admissions, and care homes - similar to the situation in other countries - have been seen as an epicentre of the pandemic in the UK. ${ }^{3}$ Their susceptibility appears to be enhanced by a combination of advanced age, the presence of diabetes and the emergence of frailty representing a 'triple jeopardy' state. ${ }^{4}$ As such, providing safe and effective care to residents with diabetes is a key challenge to the current care home workforce and, despite published comprehensive and wellreceived national guidance on care home diabetes more than a decade ago, ${ }^{5}$ a large number of care staff have received little or no training and education in even minimal diabetes care. In our view this represents a failure in care provision to the most vulnerable diabetes population. This must be seen as a shared responsibility between all relevant stakeholders, including local authorities who have the legal responsibility for care provision and generally commission care services from external independent providers. However, we also see this as an opportunity for diabetes specialists (both

Foundation for Diabetes Research in Older People (fDROP) and King's College, London, UK and Chair of the National Advisory Panel on Care Home Diabetes (NAPCHD), UK

Rotherham NHS Foundation Trust and Member of NAPCHD, UK

University of Aston and Member of NAPCHD, UK

Address for correspondence: Professor Alan Sinclair Foundation for Diabetes Research in Older People, Administrative Offices, Orkney Court, Taplow, SL60JB, Bucks. UK

E-mail: caroalan1981@gmail.com

Br J Diabetes 2021;21:173-174

https://doi.org/10.15277/bjd.2021.318 medical and nursing) to take up the baton and make Care Home Diabetes part of their developing field of Community Diabetology, with a commitment to improve standards of diabetes care within institutional and long-term settings.

Whilst most clinical care should be based on the best available evidence, it is clear that, while descriptive and observational studies of residents with diabetes in care are available, ${ }^{2,6}$ there is limited information on randomised clinical trials of interventions within care home settings ${ }^{2}$ which should be a prompt to funding organisations, major pharma and researchers to take a greater interest in this sector of the diabetes population. ${ }^{7}$ The lack of a robust evidence base creates uncertainty in clinical decisionmaking about what are the safest and most effective glucoselowering therapies to use in residents with diabetes of varying grades of multi-morbidity and frailty, and what glycaemic targets are appropriate. As a consequence, clinical guidelines on diabetes in older people rely on applying expert advice only, which may be less than satisfactory. ${ }^{8,9}$

A recent review of this area $^{2}$ emphasised that the goals of caring for residents with diabetes should evolve around prevention of frailty and disability, risk management and optimising quality of life while preserving functional status with an overall consideration of life expectancy at all levels of intervention. This endorses the principles of the philosophical framework of the Australian McKellar Guidelines on managing diabetes in residential settings. ${ }^{10}$ The review ${ }^{2}$ concluded that additional resources are required (both public and private) to establish sustainable effective diabetes care within care homes and similar settings including training and upskilling care staff, providing modern equipment for diagnosis and point of care testing (POCT), the modification of facilities to allow for implementing new interventions and undertaking regular audit programmes. This represented a 'Call to Action' to bring about a global improvement in the care of residents with diabetes.

The establishment of the National Advisory Panel on Care Home Diabetes (NAPCHD) in July 2020 by a multi-stakeholder group of organisations (including all major diabetes organisations, Royal College of General Practitioners, Care England, Queen's Nursing Institute, Care Quality Commission, Directors 
of Adults Social Services and other key representatives) was driven by several forces including the need to produce a timely document that is a decade or so on from the 2010 national Diabetes UK care home diabetes guidance. Other drivers included the need for a document that requires a broader representation from all involved stakeholders that have an influence on the nature, quality and delivery of effective diabetes care in the care home sector. In addition, the recent COVID-19 and diabetes care guidance issued by the National Diabetes Stakeholders COVID-19 Response Group (April 2020)11 revealed the high vulnerability of residents with diabetes, both to infection but also to developing serious acute medical illness. Thirteen key tasks were identified and eight subgroups among the panel members were set up. The work is due to finish in late Autumn 2021. Five key outcomes are hoped for:

1. To develop a national Strategic Document of Diabetes Care for Care Homes that will provide a set of recommendations which, if funded and implemented, will bring about worthwhile, sustainable and effective quality of diabetes care improvements that have a measurable effect on enhancing clinical outcomes, quality of life and wellbeing of all residents with diabetes. This, in principle, would represent a new model of health and social care for residents with diabetes in care homes

2. To bring about a culture change in all health and social care sectors that recognises the urgent need to fund and support the training and education of care staff to enhance their skills and abilities to deliver better quality diabetes care.

3. To bring about measurable but realistic improvements within the care home sector that will enhance the liaison with local laboratory services to enhance diagnosis, monitoring and management.

4. To create a preventative programme that minimises the risk of hospital admission of residents with diabetes.

5. To support a wider use of technology to support diagnosis, monitoring and liaison and networking between relevant community-based services, health and social care professionals and public health

At all times a caring and compassionate workforce supported by community-based health and social professionals will be needed, particularly for those residents with severe frailty and disability and those with diabetes at end of life. We feel it is also time to include Care Home Diabetes on the Specialist Training Curriculum in Diabetes \& Endocrinology as part of Community Diabetology, which could be led by ABCD and JBDS-IP working in collaboration to define the learning objectives and training format. Better research, better joined-up thinking between stakeholders and implementation of the NAPCHD work should provide a sound basis for real and consistent improvements in diabetes care delivery within care homes.

Conflict of interest None of the authors declare any conflict of interest in providing this article.

Funding No funding was received in providing this article.

\section{References}

1. Sinclair A, Saeedi P, Kaundal A, Karuranga S, Malanda B, Williams R. Diabetes and global ageing among 65-99-year-old adults: findings from the International Diabetes Federation Diabetes Atlas, 9th edition. Diabetes Res Clin Pract 2020;162:108078. https://doi.org/10.1016/j.diabres.2020.108078

2. Sinclair AJ, Gadsby R, Abdelhafiz AH, Kennedy M. Failing to meet the needs of generations of care home residents with diabetes: a review of the literature and a call for action. Diabet Med 2018;35(9):1144-56. https://doi.org/10.1111/dme.13702

3. Office for National Statistics. Deaths involving COVID-19 in the care sector, England and Wales: deaths registered between week ending 20 March 2020 and week ending 2 April 2021. Available at: https://www.ons.gov.uk

4. Sinclair AJ, Abdelhafiz AH. Age, frailty and diabetes - triple jeopardy for vulnerability to COVID-19 infection. EClinicalMedicine 2020;22:100343. https://doi.org/10.1016/j.eclinm.2020.100343

5. Diabetes UK. Good clinical practice guidelines for care home residents with diabetes. 2010. http://www.diabetes.org.uk/Documents/ About\%20Us/Our\%20views/Care\%20recs/Care-homes-0110.pdf

6. Sinclair AJ, Allard I, Bayer A. Observations of diabetes care in long-term institutional settings with measures of cognitive function and dependency. Diabetes Care 1997:20(5):778-84. https://doi.org/10.2337/ diacare.20.5.778

7. Munshi MN, Meneilly GS, Rodríguez-Mañas L, et al. Diabetes in ageing: pathways for developing the evidence base for clinical guidance. Lancet Diabetes Endocrinol 2020;8(10):855-67. https://doi.org/10.1016/ S2213-8587(20)30230-8

8. Sinclair AJ, Paolisso G, Castro M, Bourdel-Marchasson I, Gadsby R, Rodriguez Mañas L, European Diabetes Working Party for Older People. European Diabetes Working Party for Older People 2011 clinical guidelines and references for type 2 diabetes mellitus. Executive summary. Diabetes Metab 2011;37(Suppl 3):S27-38. https://doi.org/10.1016/ S1262-3636(11)70962-4

9. Dunning T, Sinclair A, Colagiuri S. New IDF Guideline for managing type 2 diabetes in older people. Diabetes Res Clin Pract 2014;103(3):53840. https://doi.org/10.1016/j.diabres.2014.03.005

10. Dunning T, Duggan N, Savage S. The McKellar Guidelines for managing older people with diabetes in residential and other care settings. 2014. Centre for Nursing and Allied Health, Deakin University and Barwon Health, Geelong, Australia. ISBN 978-0-9923333-0-0

11. Sinclair A, Dhatariya $K$, Burr $O$, et al. Guidelines for the management of diabetes in care homes during the Covid-19 pandemic. Diabet Med 2020;37(7):1090-3. https://doi.org/10.1111/dme.14317 